line treatment of uncomplicated malaria. The role of lumefantrine in this combination is to eliminate remaining parasites after the action of artemether and to protect the patient against a new blood infection. Some studies showed a correlation between lumefantrine's day 7 concentration and the efficacy of AL after treatment of a single episode of malaria. The objective of this work is to validate this observation after repetitive treatment of uncomplicated malaria patients with AL.

Methods During a phase IIIb/IV comparative, randomised, multicentre, clinical study of artemisinin-based combination therapies, we collected plasma on Day 7 from patients treated with standard dose of AL in Sotuba, Bougoula Hameau, and Kolle (Mali). The age of the patients enrolled in this study was from 6 months old. The plasma samples were kept at $-80^{\circ} \mathrm{C}$ until lumefantrine analysis using high performance liquid chromatography was performed.

Results We included 1076 subjects, of which 595 were females and a mean age of 12 years old in this analysis.

The median concentration was $66 \%$ higher $(\mathrm{p}<0.0001)$ in patients without recurrent parasite on day 28 compared to patients with recurrent parasitaemia: $509.1 \mathrm{ng} / \mathrm{ml}$ (inter quartile range: $329.6-723.2 ; \mathrm{n}=919)$ vs 372.5 (255.7-538.4; $\mathrm{n}=157)$. Day 7 concentrations increased with age; the difference between age group was statistically significant: 305.9 (207.3-491.5, $\mathrm{n}=140), 447 \quad(290.7-622.9, \mathrm{n}=399), 544.7 \quad(383.9-738.5$, $\mathrm{n}=254)$ and $571.1(378.8-850.9), \mathrm{n}=283)$ in patients under 5 years old, 5-9 years old, 10-14 years old and 15 years old and older, respectively. Girls under 5 years old had a lower lumefantrine concentration at day 7 compared to other age groups of $223.3 \mathrm{ng} / \mathrm{ml}(159.7-425.6, \mathrm{n}=37)$.

Conclusions We found a lower concentration of lumefantrine in patients with recurrent parasitaemia at day 28 .

\title{
PA-024 LUMEFANTRINE DISPOSITION AFTER REPETITIVE TREATMENT OF UNCOMPLICATED MALARIA PATIENTS WITH ARTEMETHER-LUMEFANTRINE IN MALI
}

\author{
Mamadou Tekete, ${ }^{1}$ Juergen Burhenne, ${ }^{2}$ Bakary Fofana, ${ }_{1}^{1}$ Sekou Toure, ${ }^{1}$ \\ Souleymane Dama, ${ }^{1}$ Nianwalou Dara, ${ }^{1}$ Oumar Traore, ${ }^{1}$ Bouran Sidibe, ${ }^{1}$ \\ Abdoulaye Djimde, ${ }^{1}$ Walter Haefeli, ${ }^{2}$ Steffen Borrmann ${ }^{3} .{ }^{1}$ MRTC, University of \\ Bamako, Mali; ${ }^{2}$ Heidelberg University, Germany; ${ }^{3}$ ITM Tübingen, Germany
}

10.1136/bmjgh-2016-000260.61

Background Since 2006 the national malaria control program in Mali recommended artemether-lumefantrine (AL) as the first- 